\title{
DROUGHT PREPAREDNESS STATUS OF FARMERS IN THE NGUNI CATTLE DEVELOPMENT PROJECT AND THE SIRE SUBSIDY SCHEME IN NORTH WEST PROVINCE, SOUTH AFRICA
}

\author{
BAREKI, N. P. ${ }^{1^{*}}-$ ANTWI, M. A. ${ }^{2}$ \\ ${ }^{I}$ North West Department of Rural, Environment and Agricultural Development, Animal \\ Sciences, Private Bag X804, Potchefstroom, 2520, South Africa \\ (phone: +27-18-299-6500; fax: +27-86-580-4161) \\ ${ }^{2}$ Department of Agriculture and Animal Health, University of South Africa, Private Bag X6, \\ Florida, 1710, South Africa \\ (phone: +27-11-670-9391; fax: +27-11-471-2260) \\ *Corresponding author \\ e-mail:nbareki@nwpg.gov.za \\ (Received 28 ${ }^{\text {th }}$ Mar 2017; accepted $3^{\text {rd }}$ Jul 2017)
}

\begin{abstract}
The objective of this study was to assess the drought preparedness status of the farmers that benefited from the Nguni Cattle Development Project and the Sire Subsidy Scheme in North West Province, South Africa. The data were collected using both quantitative and qualitative approaches to research, through a semi-structured questionnaire with five sections that probed into: A) personal information, B) farmer socio-economic resources, C) farm operational resources, D) access to Early Warning Information, and E) constraints to drought preparedness. Collected data were coded, captured and analysed using Microsoft Excel and SPSS (version 23) into frequency counts, percentages, graphs and tables. The results revealed that, majority of the respondents were African (97.6\%); male (74.1\%); married (64.3\%); between 50 and 64 years of age $(43.5 \%)$ and $(38.8 \%)$ had high school education, respectively. Furthermore, most (76\%) respondent farmers were not drought prepared with regard to grazing availability; $20 \%$ of the farmers were found to have non-dependable sources of water; $60 \%$ of the farms did not have any structural units for maintaining fodder banks and $63 \%$ did not have enough fodder reserves. Most respondents $(84 \%)$ had never received drought related early warning information. Respondents cited lack of money $(62 \%)$ and deficiency of information (58\%) as the major constraints to their drought preparedness. The study recommends that the agricultural extensionists' plausible contact (95\%) with the farmers should be used to also educate farmers on effective drought mitigation strategies and for dissemination of early warning information.
\end{abstract}

Keywords: climatic changes, drought mitigation, early warning information, fodder banks, spare grazing

\section{Introduction}

South Africa has recently experienced one of the worst droughts of the past century, with compromised agricultural production anticipated in the summer rainfall areas. The impact of droughts already severed the South African agricultural sector, largely affecting the extensive farming areas. In South Africa, drought has already cost farmers' losses of up to ten million rand (R10m) in 2015 (Bahta et al., 2016). Drought is however a common phenomenon in semi-arid and arid ecosystems (Coppock, 2011). Drought is furthermore the most frequent (Backeberg and Viljoen, 2003) and devastating phenomena that occurs in South Africa (Boone et al., 2004; Austin, 2008). Agricultural drought often has direct effects on the economy through the associations of agriculture 
with other sectors of the economy. This makes drought an important hazard, particularly in terms of the numbers of people affected (Coppock, 2011; Ngaka, 2012).

The uncertainty on the occurrence and magnitude of the effects of climatic changes, including the occurrence of droughts, often makes mitigation efforts quite problematic. Knowledge of the drought preparedness or vulnerability of the beneficiary farmers can assist the sector in proactive planning for drought mitigation and therefore reduce the pool of those who need relief in the event of droughts.

The North West Provincial Department of Agriculture has through its Sire Subsidy Scheme (SSS) and the North West/Industrial Development Corporation - Nguni Cattle Development Project (NW/IDC-NCDP) distributed genetic breeding material (beef cattle) to identified farmers throughout the province for over 10 years. The primary aim of the SSS is to induce herd genetic change in an attempt to improve the overall herd performance by the introduction of quality performance tested sires. The NW/IDCNCDP on the other hand, is a tripartite partnership between the Department of Agriculture, the Industrial Development Corporation (IDC) and North West University (Mafikeng Campus) (DACE, 2008, Cwaile et al., 2012). The NW/IDC-NCDP was founded in 2006 (IDC, 2007) with the main aim of reintroducing and preserving the indigenous Nguni cattle genetic pool in the province (DACE, 2008).

All of the distributed genetic material is farmed under harsh extensive conditions, notwithstanding that, extensive beef production in the semi-arid and arid regions is highly vulnerable to climatic changes. On the other hand, North West Province has, as recent as in the years 2012 to 2015 , been reported to have had the most devastating drought in 80 years. This is not surprising, considering that the year 2015 has been recorded as the driest year ever in South Africa since the recording of rainfall started in 1904 (SAWS, 2016). It is necessary therefore to collect all relevant data that could aid in assessing as to whether conditions under which the NW/IDC-NCDP and SSS cattle are farmed with, would allow for sustained production even in the event of the imminent droughts.

Drought preparedness involves vulnerability or resilience assessments, monitoring, forecasting as well as mitigation and response planning measures (Wilhite et al., 2005; Gutiérrez et al., 2014). The main objective of the study was therefore to:

a) Determine the drought preparedness status of the farmers that benefited from the NW/IDC-NCDP and SSS in the North West Province.

The specific objectives of the study were to:

a) Determine the resource drought preparedness of the beneficiary farms.

b) Identify possible factors influencing drought preparedness of farmers.

\section{Materials and Methods}

The study was conducted in North West Province which occupies a total area of 104 $882 \mathrm{~km}^{2}$, covering $8.7 \%$ of the total area of the Republic of South Africa. The province is divided into four district municipalities, namely: Dr Ruth Segomotsi Mompati in the west; Dr Kenneth Kaunda in the south; Bojanala Platinum in the east, as well as the centrally located Ngaka Modiri Molema. North West Province borders the provinces of Northern Cape in the west, Free State in the south, Gauteng in the east and Limpopo in the north-east with the Republic of Botswana in the northern side. Much of the province consists of flat areas of scattered trees and grasslands. The rainfall pattern of the 
province is highly variable, both spatially and temporally. Under normal climatic conditions, the western parts of the province receive on average less than $300 \mathrm{~mm}$ per annum, the central parts around $550 \mathrm{~mm}$ and the eastern and south-eastern parts receives over $600 \mathrm{~mm}$ per annum.

The data were collected using both quantitative and qualitative approaches to research. This was done in an effort to improve the validity, analytic power and relevance of the findings. The qualitative approach documented the respondents' perceptions and opinions through in-depth interviews while the quantitative approach was used to capture the in-situ numerical and physical observations on infrastructure. Data were collected through a semi-structured questionnaire made up of five sections, namely: A) personal information, B) farmer socio-economic resources, C) farm operational resources, D) access to Early Warning Information (EWI), and E) constraints to drought preparedness. Face to face interviews as well as physical observations, and assessment of the farms' resource base were used to collect the data. An inclusive total of 85 beneficiaries from all four districts of North West Province were interviewed in this study. The collected data were coded, captured and analysed using Microsoft Excel (2010) and SPSS (version 23) into frequency counts, percentages, graphs and tables.

The SSS had not been rolled out in all the districts and therefore, proportional representation of the SSS against the NW/IDC-NCDP could not be achieved (Fig. 1). Only beneficiaries who were actively involved in the project were targeted for the NW/IDC-NCDP. This was because, once the beneficiaries have returned their loaned cattle, there is essentially no contractual obligation on their part to partake in departmental programmes.

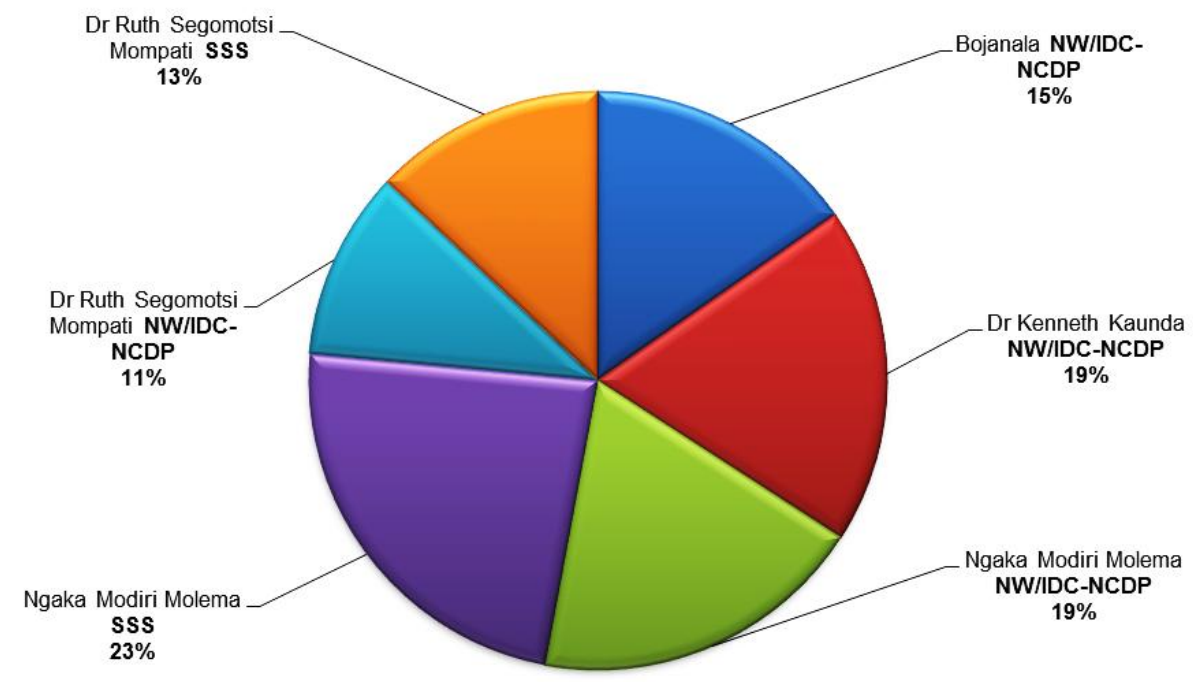

Figure 1. Data origin and distribution per district

\section{Results}

\section{Socio-economic and demographic characteristics of the respondents}

The distribution of respondents according to various socio-economic and demographic characteristics is summarised in Table 1 . The results revealed that most of 
the respondents were African (97.6\%), male (74.1\%), married (64.3\%), between 50 and 64 years of age $(43.5 \%)$ and $(38.8 \%)$ had high school education, respectively. For the purposes of this report, high school education refers to educational programmes consisting most commonly of students/pupils enrolled in grades 10 through to 12. A noticeable number of the respondents $(31.8 \%)$ had tertiary education. Most respondents (49.4\%) had a substantial household size of about 5 to 8 members. This is so despite most respondents $(51.2 \%)$ having on average, 1 to 3 dependants. The results further show that young farmers (aged 34 years and less) accounted for only 9.4\% of the respondents. More than half $(51.8 \%)$ of the respondent farmers never received any training or short courses in agriculture.

Table 1. Socio-demographic characteristics of respondents

\begin{tabular}{|c|c|c|c|}
\hline Characteristic & Sub-characteristic & Frequency & Percentage \\
\hline \multirow{3}{*}{ Gender } & Female & 18 & 21.2 \\
\hline & Male & 63 & 74.1 \\
\hline & Group with both genders & 4 & 4.7 \\
\hline \multirow[t]{5}{*}{ Age } & $20-34$ & 8 & 9.4 \\
\hline & $35-49$ & 20 & 23.5 \\
\hline & $50-64$ & 37 & 43.5 \\
\hline & $65-79$ & 18 & 21.2 \\
\hline & $\geq 80$ & 2 & 2.4 \\
\hline \multirow[t]{4}{*}{ Marital status } & Single & 22 & 26.2 \\
\hline & Married & 54 & 64.3 \\
\hline & Widowed & 6 & 7.1 \\
\hline & Divorced & 2 & 2.4 \\
\hline \multirow[t]{3}{*}{ Race } & African & 83 & 97.6 \\
\hline & Coloured & 1 & 1.2 \\
\hline & Indian & 1 & 1.2 \\
\hline \multirow[t]{4}{*}{ Dependants } & 0 & 8 & 9.5 \\
\hline & $1-3$ & 43 & 51.2 \\
\hline & $4-6$ & 27 & 32.1 \\
\hline & $7-9$ & 6 & 7.2 \\
\hline \multirow[t]{3}{*}{ Household size } & $1-4$ & 35 & 41.2 \\
\hline & $5-8$ & 42 & 49.4 \\
\hline & $9-12$ & 7 & 8.2 \\
\hline \multirow[t]{5}{*}{ Educational } & None & 2 & 2.3 \\
\hline & Primary & 13 & 15.3 \\
\hline & Secondary & 10 & 11.8 \\
\hline & High School & 33 & 38.8 \\
\hline & Tertiary & 27 & 31.8 \\
\hline \multirow[t]{2}{*}{ Agriculture short courses } & Yes & 41 & 48.2 \\
\hline & No & 44 & 51.8 \\
\hline
\end{tabular}




\section{Farmer socio-economic resources}

The results revealed that $88 \%$ of the respondents were full-time farmers and only $8 \%$ of them were farming on a part time basis (Table 2). Groups that included both full time and part time farmers represented a very small part $(4 \%)$ of the respondents. Furthermore, $73 \%$ of the respondent famers did not engage in non-farming business activities. The results further revealed that $76 \%$ of the respondents had no other income to help them during droughts.

Table2. Summary of responses on farmer socio-economic resources

\begin{tabular}{lccc}
\hline Characteristic & Sub-characteristic & Frequency & Percentage \\
\hline Type of farmer? & Full time & 75 & 88 \\
& Part time & 7 & 8 \\
& Both (as a group) & 3 & 4 \\
Do you engage in non-farming business & & & \\
activities? & Yes & 23 & 27 \\
Do you have other income to help you & No & 62 & 73 \\
during droughts? & Yes & 20 & 24 \\
\hline
\end{tabular}

\section{Farm operational resources}

Responses and observations on farm operational resources in relation to available grazing are summarised in Table 3. On farm observations revealed that only 43 (51\%) of the respondent farms seemed to have reasonable amounts of grazing for a season. Of the 43 farms, 31 (72\%) had enough grazing to last for 5 to 6 months. The remaining farms had either enough grazing for 1 to 2 months (9\%) or 3 to 4 months (19\%). However, from the 43 farms with reasonable amounts of grazing, only 35 (41\%) had spare or reserved grazing, of which only $57 \%$ of such spare grazing could sustain a herd of cattle for 5 to 6 months. In essence, out of the studied population (85), only 31 (36\%) of the farms had enough grazing to last for 5 to 6 months, and only 20 (24\%) of these farms had enough spare grazing to last for 5 to 6 months. These results indicate therefore that the remaining $65(76 \%)$ respondent farms did not have enough grazing to sustain their cattle for two seasons of the year.

It is further revealed in Table 3 that boreholes were the most prominent $(86 \%)$ source of drinking water for cattle. The majority of the respondents rated their sources of water as either highly dependable $(54 \%)$ or dependable $(26 \%)$. The remaining respondents $(20 \%)$ who rated their water source as non-dependable, had either a too small/nonfunctional reservoir or only one borehole (16\%), whereas a minority $(4 \%)$ had no source of water at all on the farm.

Table 3 also shows that $60 \%$ of the respondent farms did not have any structural units for maintaining fodder banks. Furthermore, $84 \%$ of the respondent farms did not have enough fodder reserves. The reasons advanced by farmers for not having stored fodder are also summarised in Table 3. Of the 84\% respondents without enough stored fodder, only $21 \%$ had at least enough standing hay as back-up fodder for periods of shortages. The remaining $63 \%$ did not have enough fodder reserves. It is worth mentioning that among the reasons advanced for not maintaining fodder banks, the combined frequencies of "lack of knowledge" and "ignorance" accounts for $38 \%$ of the 
reasons why respondents did not have any fodder stored. Lack of funds accounted for a further $23 \%$, whereas lack of infrastructure and equipment respectively accounted for $17 \%$ and $1 \%$ of the reasons why respondents had no reserved fodder.

Table 3. Summary of responses and observations on farm operational resources

\begin{tabular}{|c|c|c|c|}
\hline Characteristic & Sub-characteristic & Frequency & Percentage \\
\hline \multirow{2}{*}{ Does the farm have enough grazing? } & Yes & 43 & 51 \\
\hline & No & 42 & 49 \\
\hline \multirow[t]{3}{*}{ If yes, for how long? } & $1-2$ months & 4 & 9 \\
\hline & 3-4 months & 8 & 19 \\
\hline & 5-6 months & 31 & 72 \\
\hline \multirow{2}{*}{$\begin{array}{l}\text { Does the farm have spare grazing for the } \\
\text { herd? }\end{array}$} & Yes & 35 & 41 \\
\hline & No & 50 & 59 \\
\hline \multirow[t]{3}{*}{ If yes, for how long? } & $1-2$ months & 5 & 14 \\
\hline & 3-4 months & 10 & 29 \\
\hline & $5-6$ months & 20 & 57 \\
\hline \multirow{2}{*}{$\begin{array}{l}\text { Does the farm have adequate fodder } \\
\text { banks? }\end{array}$} & Yes & 34 & 40 \\
\hline & No & 51 & 60 \\
\hline \multirow{2}{*}{$\begin{array}{l}\text { Does the farm have enough fodder in } \\
\text { fodder banks? }\end{array}$} & Yes & 13 & 15 \\
\hline & No & 71 & 84 \\
\hline What is your source of water for cattle & Borehole & 73 & 86 \\
\hline \multirow{2}{*}{ How dependable is your water source } & $\begin{array}{c}\text { Dependable to Highly } \\
\text { dependable }\end{array}$ & 68 & 80 \\
\hline & Not dependable & 17 & 20 \\
\hline \multirow[t]{6}{*}{ Reasons for not having stored fodder } & No infrastructure & 12 & 17 \\
\hline & No funds & 17 & 23 \\
\hline & Lack of knowledge & 12 & 17 \\
\hline & Ignorance (Do not know) & 15 & 21 \\
\hline & $\begin{array}{l}\text { Have enough standing hay } \\
\text { (grazing) }\end{array}$ & 15 & 21 \\
\hline & Lack of equipment & 1 & 1 \\
\hline
\end{tabular}

\section{Source of extension messages}

Figure 2 shows that $95 \%$ of the respondents had contact with agricultural extensionists and that $64 \%$ of such contact was on a regular basis. The main source of extension messages (94\%) with regard to drought were reported to be from government extension services (Fig. 3). This can be expected given that $65 \%$ of the respondents did not belong to any farmer association or organised agriculture groupings. A negligible number $(6 \%)$ of respondents received extension messages from non-governmental sources as well. 


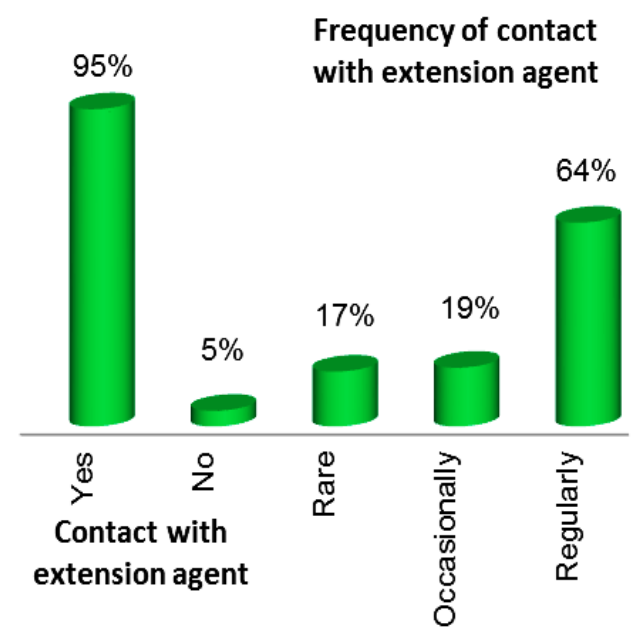

Figure 2. Respondents' contact with extension agents

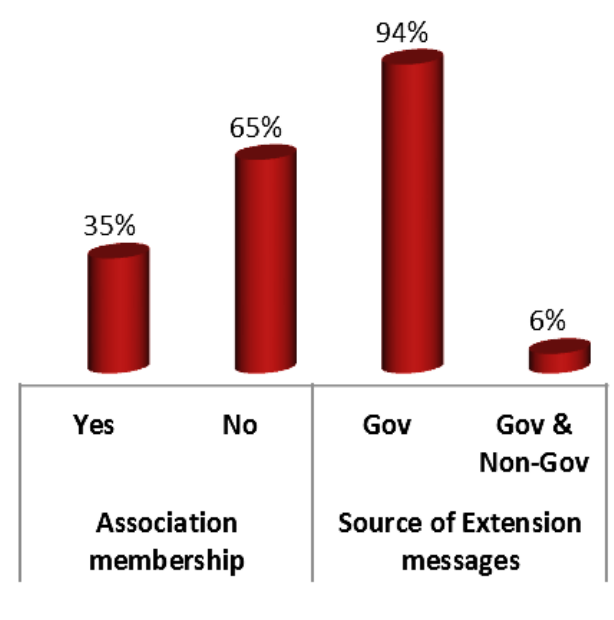

Figure 3. Membership of associations and source of extension messages

\section{Early warning information}

Access to early warning information and drought planning among the respondent farmers is summarised in Table 4. The results indicate that $98 \%$ of the respondents reported that they earnestly need EWI, and $91 \%$ of them expect such information to come from the state extension services.

Table 4. Access to early warning information and drought planning

\begin{tabular}{lccc}
\hline Characteristic & Sub-characteristic & Frequency & Percentage \\
\hline Have you directly received any advice on & Yes & 15 & 18 \\
what to do before and during drought? & No & 70 & 82 \\
$\begin{array}{l}\text { Have you directly received any EWI about } \\
\text { drought? }\end{array}$ & Yes & 14 & 16 \\
Do you need EWI for drought preparation? & No & 71 & 84 \\
& Yes & 83 & 98 \\
& No & 2 & 2 \\
From where can you get expert & Extension Officers (EO) & 77 & 91 \\
advice/information about drought? & EO and SA Weather & 3 & 3 \\
& services & 4 & 5 \\
& I do not know & 1 & 1 \\
Do you have an existing drought plan? & Climatologists & 37 & 44 \\
& Yes & 48 & 56 \\
Reasons for not having a drought plan? & No & 40 & 73 \\
& Lack of knowledge & 14 \\
& The farm has enough & 8 & 6 \\
& standing hay & 3 & 7 \\
\hline
\end{tabular}


However, $84 \%$ of the farmers have never directly received EWI with reference to neither their specific farming area nor their farms. Furthermore, $82 \%$ of the respondents reported that they have never directly received advice on what to do before or during drought for purposes of enhancing their drought preparedness. More than half $(56 \%)$ of the farmers did not have any drought mitigation plan at all. Table 4 further revealed that $73 \%$ of the respondents cited lack of knowledge as the major reason for not having any drought plan.

\section{Land utilisation}

Proportional land use subdivisions among respondent farms are summarised in Table 5. The individual farm sizes vary considerably within and across district municipalities and range from 4 hectares in Ngaka Modiri Molema to 3600 hectares in Dr Ruth Segomotsi Mompati. The average farm size for the studied population was found to be 709.51 ha with a standard deviation equalling 507.94. Most of the respondents are farming extensively on veld $(89 \%)$ with very little (4\%) planted pastures (Table 5). The available arable land $(7 \%)$ is often cultivated and of reasonable use to livestock for drought preparedness purposes.

Table 5. Farm land (ha) size statistics and proportional subdivision

\begin{tabular}{ccccc}
\hline \multirow{2}{*}{ Item } & \multicolumn{3}{c}{ Comparative land subdivision } & \\
\cline { 2 - 4 } $\boldsymbol{N}(\mathbf{7 1})$ & Portion veld & Portion pasture & Portion arable & Total land size \\
\hline Mean & 635.01 & 25.68 & 47.67 & 709.51 \\
S.D. & 517.61 & 83.18 & 89.12 & 507.94 \\
Min & 2 & 10 & 2 & 4 \\
Max & 3600 & 430 & 388 & 3600 \\
Sum & 45094 & 1849 & 3432 & 50375 \\
Proportional use & $89 \%$ & $4 \%$ & $7 \%$ & $100 \%$ \\
\hline
\end{tabular}

\section{Farm size and livestock statistics}

Farm size and livestock statistics per district are summarized in Table 6. On average, the largest farms were observed in Dr Ruth Segomotsi Mompati, and respectively followed by the Dr Kenneth Kaunda; Bojanala Platinum and Ngaka Modiri Molema districts. The largest herds (mean) were surprisingly observed from the Dr Kenneth Kaunda district (113) followed by Bojanala platinum district (71). The herds with the least number of cattle (2 and 17) were observed from the Dr Ruth Segomotsi Mompati and Ngaka Modiri Molema districts respectively. The results with regard to farm and herd sizes are not surprising, and are largely in accordance with the grazing potential (natural veld) of the specific areas (Fig. 5) in terms of hectares per large stock unit (ha/LSU). For instance, the smallest herd ( 2 cattle) was observed from a communal area in Taung with a grazing potential of $20-25$ ha/LSU, followed by herds from the Mafikeng area with a grazing potential of $18 \mathrm{ha} / \mathrm{LSU}$ (Fig. 5).

Grazing in Dr Ruth Segomotsi Mompati was mainly made up of natural veld (100\%), followed by the Bojanala Platinum district (96\%) and Dr Kenneth Kaunda district $(84 \%)$ as well as Ngaka Modiri Molema (79\%). In addition to natural grazing, the balance of land utilization percentages in Table 6 represented arable land under dryland production as well as cultivated pastures. 
The majority of the farms are leased (61\%) and only $14 \%$ of respondents own the land that they are farming on (Fig. 4). This may be contributory to the observed frequency $(17 \%)$ of "no infrastructure" regarding lack of fodder banks in Table 3, as farmers may be reluctant to make improvements on leased land. A further $17 \%$ and $8 \%$ of the land was respectively utilized through communal and tribal allocation.

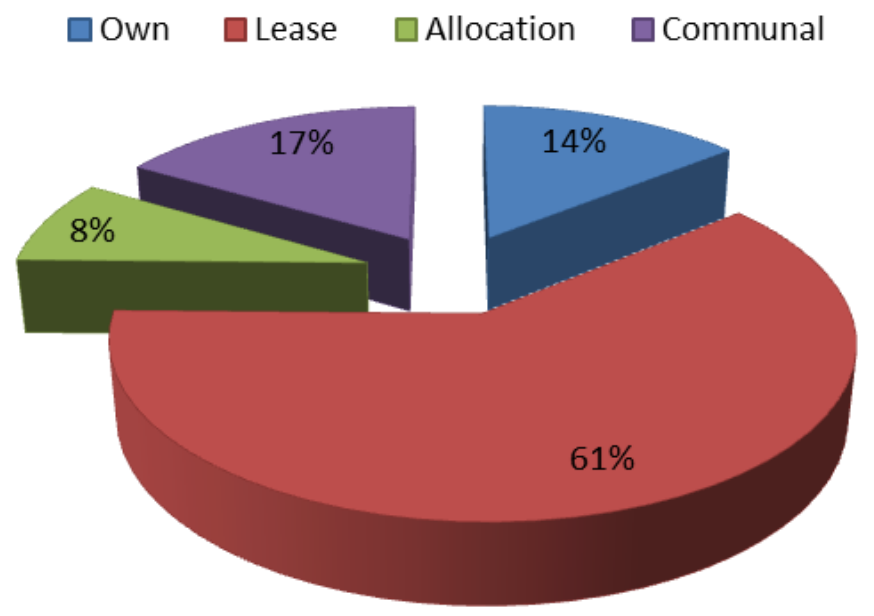

Figure 4. Land ownership

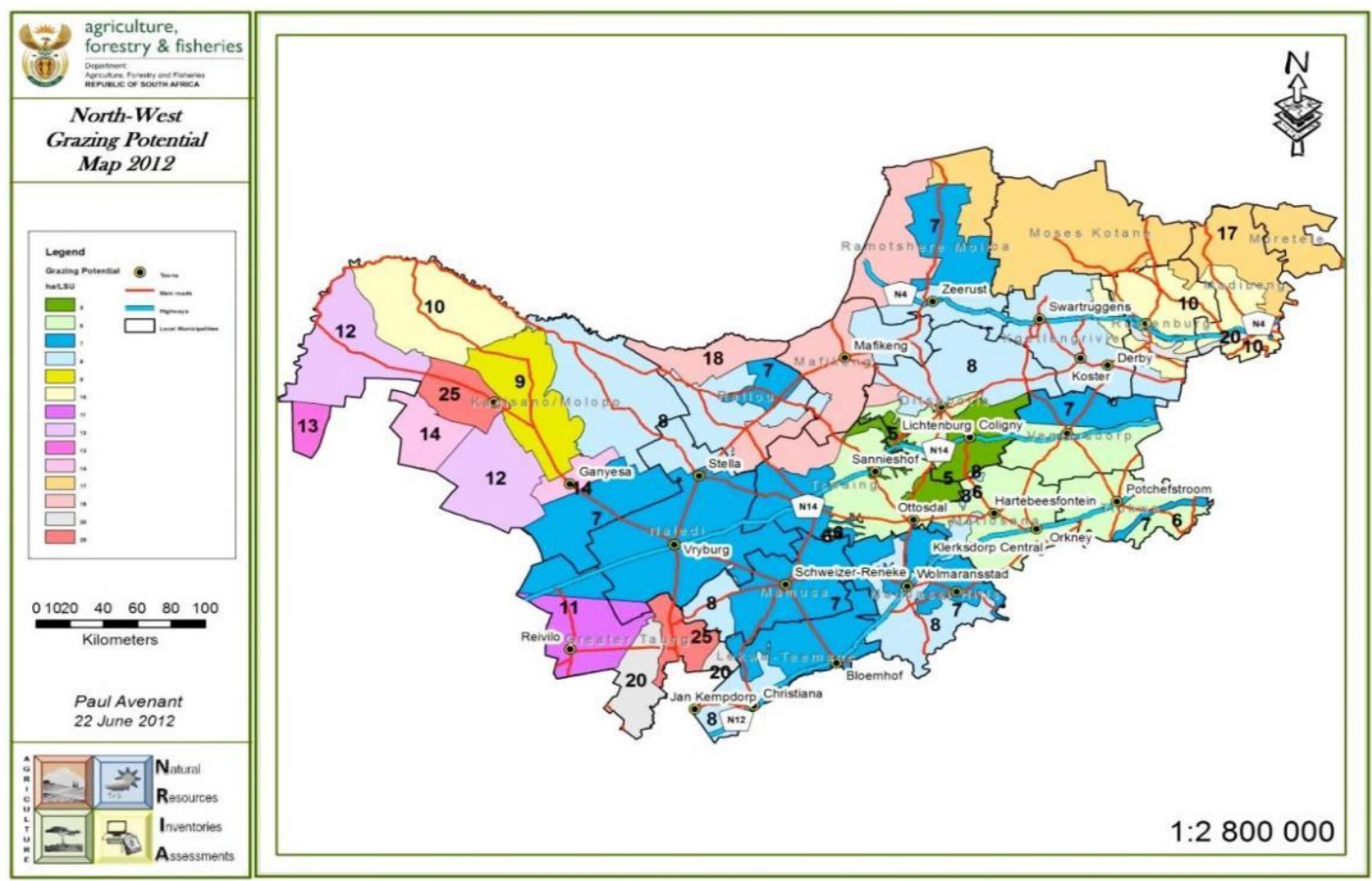

Figure 5. Grazing potential map for North West Province, South Africa 
Table 6. Summarized farm size and cattle statistics per district (cattle in parenthesis)

\begin{tabular}{ccccc}
\hline Item & $\begin{array}{c}\text { Dr Ruth } \\
\text { Segomotsi } \\
\text { Mompati }\end{array}$ & $\begin{array}{c}\text { Dr Kenneth } \\
\text { Kaunda }\end{array}$ & Bojanala & $\begin{array}{c}\text { Ngaka Modiri } \\
\text { Molema }\end{array}$ \\
\hline$n$ & 17 & 16 & 13 & 25 \\
Land size (ha) & & & & \\
Mean & $978(64)$ & $723(113)$ & $592(71)$ & $579(64)$ \\
Min & $314(2)$ & $250(35)$ & $340(33)$ & $4(17)$ \\
Max & $3600(110)$ & $1777(297)$ & $1000(110)$ & $1600(194)$ \\
& & 84 & 96 & 79 \\
\hline
\end{tabular}

\section{Constraints to drought preparedness}

Out of a number of possible constraints to drought preparedness, mainly three constraints were cited by all respondents (Table 7). It is revealed in Table 7 that lack of government support was the least $(42 \%)$ of the constraints to drought preparedness. However, lack of money (62\%), followed by lack of information $(58 \%)$ were cited as the two biggest constraints to drought preparedness.

Table 7. The most cited constraints to drought preparedness

\begin{tabular}{cccc}
\hline Factor & Sub-factor & Frequency & Percentage \\
\hline \multirow{2}{*}{ Lack of government support } & Yes & 36 & 42 \\
& No & 49 & 58 \\
Lack of information & Yes & 49 & 58 \\
& No & 36 & 42 \\
Lack of money & & & \\
& Yes & 53 & 62 \\
& No & 32 & 38 \\
\hline
\end{tabular}

\section{Discussion}

Socio-demographic characteristics are of significant importance when studying drought preparedness or vulnerability of farmers. This is because the socio-demographic characteristics are likely to have varied influence on human behaviour in response to drought. For example, Raphael et al. (2009) found that the odds of perceived drought being very likely to continue, were significantly higher in women than in men when considering the concern for self or family. Similarly, some studies found that as a demographic characteristic, gender had a critical influence in decisions on drought and agricultural activities (Bahta et al., 2016; Muyambo et al., 2017). The results confirm that animal production is a male dominated career in the studied area, with very little youth involvement. In agreement, Cwaile et al. (2012) found the majority of the Nguni cattle beneficiaries to be males aged above 60 years, and Oladele et al. (2013) found that the youth accounted for only about $(7 \%)$ of respondents in their study. The lower level of participation of younger persons in this study is suggestive of compromised youth empowerment with reference to the two schemes understudy. The lower participation of the youth may be further exacerbated by capital requirements for cattle 
farming, particularly access to land. Youth within close proximity of the surveyed demographic population did not own or have much access to land and therefore had limited chances of participating in cattle farming. In line with these socio-demographic characteristics, it is not surprising that the majority of respondent farmers were not drought prepared.

The finding on respondent education is in agreement with the national census (Stats SA, 2011), which declared that among the South African population, $35.2 \%$ of black/African citizens have completed an education level of high school or higher. However, this level of education did not seem to encourage drought preparedness in anyway.

The results on farmer socio-economic resources suggest that the majority of the respondents have ample opportunity to decisively focus on farming activities, including drought preparedness. The results further confirm that a great majority of the farmers are dependent on their farming enterprises for income. It is therefore important for these famers to be drought prepared since their entire livelihood is dependent on their farming enterprises.

Considering that all the farms are managed as extensive farming units, a conclusion can be drawn from the result on farm operational resources that the respondents were already prone to grazing shortages and therefore vulnerable to drought at the time of the study. These findings point to a worrisome scenario, particularly when considering that the frequency and impact of natural disasters like drought has significantly increased in recent years (Ngaka, 2012), with further increase in rainfall variability expected for Southern Africa (Van Riet, 2012). In addition, North West Province has as recent as 2015 , been reported to have experienced the most devastating drought in about 80 years.

Fodder banks are concentrated units of stored forage, established for storing and providing additional feed for livestock during the dry season or periods of extended grazing shortages. The frequency of "lack of funds" as a reason for not having fodder banks is suggestive that the affected farming enterprises do not generate enough income to cater for drought preparedness activities.

There is general consensus that, farm adaptability is an important link between sustainable agriculture and drought vulnerability (Wall and Smit, 2005; Thomas et al., 2007; Bryan et al., 2009; Knutson et al., 2011). Efforts should therefore be made to enhance farm adaptability to climatic changes and consequently to drought. This is more so when considering that, it is often necessary for farmers to make certain climate influenced decisions several months before the impact of the climate variation is realized (Vogel et al., 2000; Du Plessis and Van der Waal, 2004).

Literature predictions suggest that, the effects of climate change on the southern hemisphere will present more frequent and pronounced periods of droughts (Bryan et al., 2009; Meissner et al., 2013; Scholtz et al., 2013). Therefore, although $80 \%$ of the respondents had dependable to highly dependable sources of water, South Africa is a water stressed country and a need to plan for periods of hydrological droughts and manage water availability as well as accessibility remains very important. The desirable availability of water in this study should be interpreted with caution, particularly because hydrological drought tends to lag behind meteorological drought with some temporal margin. For instance, Edossa et al. $(2010 ; 2014)$ found that the lag time between the hydrological and meteorological drought events is often in the range of 4 12 months. 
The observed plausible contact with agricultural extensionists in this study is probably encouraged by the fact that, regular monitoring of the projects is an inherent job expectation on the part of the agricultural extensionists. It is however surprising that the levels of awareness of the respondents with regard to drought preparedness and EWI does not correspond to the reported magnitude of contact with agricultural extensionists. This result is suggestive of a discord with regard to the relevance of the extension messages delivered on the observed contact junctures. In support, Maphodi et al. (2014) postulated that lack of adequate and relevant updated knowledge on various subject areas by agricultural extension officers might be the stumbling block for useful agricultural extension services to be rendered.

The results suggest that there is a pronounced inadequacy with regard to dissemination of EWI to farmers particularly with regard to droughts. This may consequently explain in part why $56 \%$ of the respondents did not have any existing drought plan. This is of concern, particularly when considering that most of the respondents had regular contact with agricultural extension services. The inadequacy in the dissemination of EWI on drought in the study area is a direct challenge to both the departmental Disaster Risk Management (DRM) and the agricultural extension services. The responsibility of the dissemination of any agricultural drought related information is therefore squarely on government, particularly by agricultural extension services. This is more so when considering that the results further showed that $65 \%$ of respondents were not affiliated to any farmer's association and $94 \%$ of the received extension messages, were from government extension services.

A conundrum remains, if extensionists are having such plausible contact (95\%) with the studied farmers, how does it happen that $84 \%$ of these farmers have never received EWI and were never instructed on drought mitigation strategies? While this question remains a subject of a different study, this puzzle is nonetheless further suggestive of a discord of responsibilities between extension services and DRM within the provincial department of agriculture. Additionally, these findings highlight in essence, the possible need to provide intensive extension workers' training on interpretation and conversion of EWI into extension messages.

The large standard deviation in land utilisation indicates the degree to which individual farms differ from the overall mean of all surveyed farms. This is suggestive of a large size variation between farms. As a result therefore, all assistance for drought preparedness will need to be tailor-made, since one strategy may not be applicable to all farms. Furthermore, both extensive beef and dryland production systems as depicted from this study are highly dependent on climatic conditions, consequently increasing the vulnerability prospects of the respondents to climatic variations, particularly drought. This is of great concern, particularly when considering the general consensus that southern Africa will become warmer and drier (Meissner et al., 2013) with overall increases in drought frequency (O'Farrell et al., 2009). These impacts can be expected to amplify the vulnerability of livestock production systems (Gill and Smith, 2008; Rust and Rust, 2013).

The results on herd size are contrary to the findings of Stats SA. (2011), where the largest herds in the country were observed in the Dr Ruth Segomotsi Mompati district. This contrast is probably as a result of the effects of the recent droughts, where areas with less rainfall had the most stock reductions.

It can be deduced from these results that more than half of the respondents are satisfied with government support in general but have significant challenges with 
funding and relevant knowledge/information on drought mitigation strategies as well as preparedness. Similarly, Maphodi et al. (2014) found that although $84.7 \%$ of farmers had access to government support, $84.2 \%$ of them indicated that they had financial problems. The role of government regarding financial assistance to farmers, and that of extensionists in educating farmers on effective drought management strategies can as a result never be over emphasised.

\section{Suggestions and conclusion}

\section{Suggestions for drought preparedness}

The high frequency of drought vulnerability among the farmers, as well as the looming climate change and its associated effects suggests a need for proactive farm management practices and interventions, in preparation for drought eventualities. To ensure the realisation of drought preparedness of the surveyed farmers, the following interventions are suggested:

- Agricultural extensionists should acquire foreknowledge and information on anticipated climatic changes, for them to be able to timeously guide and assist vulnerable farmers with regard to mitigation and coping strategies.

- Famers need to appropriately manage their production systems to achieve high operational efficiency for income generation, in order for drought preparedness costs to be absorbed by their operations.

- The extensionists' plausible contact with famers should among other things, be used to educate farmers on proactive resource management for enhancing farm adaptability to climatic changes as well as on effective drought mitigation strategies for increasing farm resilience.

- The provincial department of agriculture should develop and enforce an obligatory institutional information exchange protocol between DRM and extension services for EWI.

- The provincial department of agriculture should prioritise the development and dissemination of EWI to administrative officials and farmers respectively.

- Subsequently, concerted efforts on the part of extension services should be made to repackage extension messages in such a way that they are spatially and temporally relevant to drought related needs of the farmers, and to create avenues on which regular area specific updates can be delivered to farmers.

\section{Conclusion}

This study revealed that the majority of farmers were not drought prepared and had very little knowledge regarding drought planning and management thereof. Grazing availability was exclusively a key determinant of drought vulnerability. Access to drinking water for cattle seemed to have less influence on the vulnerability of the surveyed respondents. A pronounced inadequacy with regard to dissemination of EWI to farmers particularly with regard to droughts was observed. Agricultural extensionists had a plausible contact with most farmers on a regular basis. Such contact was however not used to educate farmers on effective drought mitigation strategies. 
Acknowledgements. The authors gratefully acknowledge all the co-workers who assisted with the collection of data. Gratitude also goes to $\mathrm{Mr} \mathrm{T}$ Kepadisa who coordinated and facilitated all data collection meetings in the Ngaka Modiri Molema District.

\section{REFERENCES}

[1] Austin, W.D. (2008): Drought in South Africa: lessons lost and/or learnt from 1990 to 2005. - MSc. Thesis, University of the Witwatersrand, Johannesburg, South Africa.

[2] Backeberg, G.R., Viljoen, M.F. (2003): Drought Management in South Africa. - Paper presented at a Workshop of the ICID Working Group on Irrigation under Drought and Water Scarcity, Tehran, I. R. of Iran. July 2003.

[3] Bahta, Y.T., Jordaan, A., Muyambo, F. (2016): Communal Farmers' perception of drought in South Africa: Policy implication for drought risk reduction. - International Journal of Disaster Risk Reduction 20: 39-50. http://dx.doi.org/10.1016/j.ijdrr.2016.10.007

[4] Boone, R.B., Galvin, K.A., Coughenour, M.B., Hudson, J.W., Weisberg, P.J., Vogel, C.H., Ellis, J.E. (2004): Ecosystem modelling adds value to a South African climate forecast. - Climatic Change 64(3): 317-340.

[5] Bryan, E., Deressa, T.T., Gbetibouo, G.A., Ringler, C. (2009): Adaptation to climate change in Ethiopia and South Africa: options and constraints. - Environmental Science and Policy 12: 413-426.

[6] Coppock, D.L. (2011): Ranching and multiyear droughts in Utah: production impacts, risk perceptions, and changes in preparedness. - Rangeland Ecology and Management 64: 607-618. http://www.ag.utah.gov/documents/rangelandecology.pdf.

[7] Cwaile, L., Antwi, M. A., Oladele, O. I. (2012): Impact that the Nguni cattle project have on the livelihood of the beneficiaries in North West province South Africa. - Journal of Food, Agriculture \& Environment 10(3\&4): 1575-1580.

[8] Department of Agriculture, Conservation and Environment (DACE). (2008): Indigenous breed re-introduced in the province. Letsema. Available from:

http://www.nwpg.gov.za/Agriculture/document/Final\%20Design_Letsema.pdf .

[Accessed 12 $2^{\text {th }}$ June 2017].

[9] Du Plessis, I., Van der Waal, C. (2004): A decision making model for stable beef production in arid environments. - S. A.-Anim. Science 5: 39-44.

[10] Edossa, D.C., Babel, M.S., Gupta, A.D. (2010): Drought analysis in the Awash River Basin, Ethiopia. - Water Resources Management 24(7): 1441-1460.

[11] Edossa, D.C., Woyessa, Y.E., Welderufael, W. A. (2014): Analysis of Droughts in the Central Region of South Africa and their association with SST Anomalies. - International Journal of Atmospheric Sciences. http://dx.doi.org/10.1155/2014/508953

[12] Gill, M., Smith, P. (2008): Mitigating climate change: the role of livestock in agriculture. - Livestock and Global Change Conference Proceedings. May 2008, Tunisia.

[13] Gutiérrez, A.P.A., Engle, N.L., De Nys, E., Molejón, C., Martins, E.S. (2014): Drought preparedness in Brazil. - Weather and Climate Extremes 3: 95-106.

[14] Industrial Development Corporation (IDC). (2007): Rural communities benefiting from unique Nguni Cattle Project. - Access, 1. Available from:

http://www.idc.co.za/access/includes/htmlnewsletter/cattle.html. [Accessed $08^{\text {th }}$ September 2014].

[15] Knutson, C.L., Haigh, T., Hayes, M.J., Widhalm, M., Nothwehr, J., Kleinschmidt, M., Graf, L. (2011): Farmer perceptions of sustainable agriculture practices and drought risk reduction in Nebraska, USA. - Renewable Agriculture and Food Systems 26(3): 255-266.

[16] Maphodi, T.H., Antwi, M.A., Ravhuhali, K.E., Lefophane, H.M. (2014): Analysing socio-economic factors influencing the failure of land reform agricultural projects in 
Ngaka Modiri Molema District of North-West Province, South Africa. - Net Journal of agricultural Science 2(2): 58-67.

[17] Meissner, H.H., Scholtz, M.M., Engelbrecht, F.A. (2013): Sustainability of the South African livestock sector towards 2050 Part 2: Challenges, changes and required implementations. - South African Journal of Animal Science 43(3): 299-319.

[18] Muyambo, F., Jordaan, A.J., Bahta, Y.T. (2017): Assessing social vulnerability to drought in South Africa: Policy implication for drought risk reduction. - Journal of Disaster Risk Studies 9(1), Art. 326. https://doi. org/10.4102/jamba.v9i1.326

[19] Ngaka, M.J. (2012): Drought preparedness, impact and response: A case of the Eastern Cape and Free State provinces of South Africa. - Journal of Disaster Risk Studies 4(1): Art. 47. http://dx.doi. org/10.4102/jamba.v4i1.47

[20] O'Farrell, P.J., Anderson, P.M.L., Milton, S.J., Dean, W.R.J. (2009): Human response and adaptation to drought in the arid zone: lessons from southern Africa. - South African Journal of Science 105: 34-39.

[21] Oladele, O.I., Antwi, M.A., Kolawole, A.E. (2013): Factors affecting livestock farmers' perception of risk of diseases in along villages along South Africa and Namibia. - Journal of Animal and Veterinary Advances 12(2): 173-176.

[22] Raphael, B., Taylor, M., Stevens, G., Barr, M., Gorringe. M., Agho, K. (2009): Factors associated with population risk perceptions of continuing drought in Australia. Australian Journal of Rural Health 17(6): 330-337.

[23] Rust, J.M., Rust, T. (2013): Climate change and livestock production: a review with emphasis on Africa. - South African Journal of Animal Science 43(3): 256-267.

[24] Scholtz, M.M., McManus, G., Leeuw, K-C., Louvandini, H., Seixas, L., Demelo, C.B., Theunissen, A., Neser, F.W.C. (2013): The effect of global warming in developing countries of the southern hemisphere. - Natural Science 5: 109-119. http://www.scirp.org/journal/ns/

[25] South African Weather Service (SAWS). (2016): General information South Africa Annual total rainfall. Public Document, CLS-CI-INFO-110.1

[26] STATS SA - Statistics South Africa. (2011): Census 2011, Agricultural households, Stats SA Library Cataloguing-in-Publication (CIP) Data, Report No. 03-11-01 (2011). Published by Statistics South Africa, Pretoria, South Africa.

[27] Thomas, D.S., Twyman, C., Osbahr, H., Hewitson, B. (2007): Adaptation to climate change and variability: farmer responses to intra-seasonal precipitation trends in South Africa. - Climatic change 83(3): 301-322.

[28] Van Riet, G. (2012): Recurrent drought in the Dr Ruth Segomotsi Mompati District Municipality of the North West Province in South Africa: An environmental justice perspective. - Journal of Disaster Risk Studies 4(1): Art. 52. http://dx.doi. org/10.4102/jamba.v4i1.52

[29] Vogel, C.H., Laing, M., Monnik, K. (2000): Drought in South Africa, with special reference to the 1980-94 Period. - In: D. A. Wilhite (ed.) Drought Volume 2: A Global Assessment, pp. 348-367.Routledge, London.

[30] Wall, E., Smit, B. (2005): Climate change adaptation in light of sustainable agriculture. Journal of Sustainable Agriculture 27: 113-123.

[31] Wilhite, D.A., Hayes, M.J., Knutson, C.L. (2005): Drought preparedness planning: Building institutional capacity. - In: D. A. Wilhite (ed.) Drought and water crises: Science, technology, and management issues, pp. 93-136. CRC Press, Boca Raton, Florida. 